\title{
Submitted: Evaluation of the visibility of peri-implant bone defects Accepted: using ultrasonography with two types of probes
} 24.02.2021

Published: 16.08.2021

\author{
Kaan Orhan ${ }^{1,2}$, Gozde Serindere ${ }^{3}$, Ceren Aktuna Belgin 3 , \\ Mehmet Hakan Kurt ${ }^{1}$ \\ ${ }^{1}$ Department of Dentomaxillofacial Radiology, Ankara University, Faculty of Dentistry, Turkey \\ ${ }^{2}$ Medical Design Application and Research Center (MEDITAM), Ankara University, Turkey \\ ${ }^{3}$ Department of Dentomaxillofacial Radiology, Hatay Mustafa Kemal University, Faculty of \\ Dentistry, Turkey
}

Correspondence: Gozde Serindere, e-mail: gozdeserindere@mku.edu.tr

DOI: $10.15557 / \mathrm{JoU} .2021 .0033$

Keywords

bone defects, cone-beam computed tomography, implant dentistry, ultrasonography

\begin{abstract}
Background: The aim of the present study was to evaluate the efficacy of intraoral and extraoral ultrasonography evaluations performed with two different types of probes (linear and "hockey stick") for the visibility of peri-implant bone defects. Material and methods: Fourteen implants were inserted into sheep heads. Peri-implant bone defects were created without knowing the depth, which served as the gold standard for the defects. The defects were scanned with two different probe types (linear and hockey stick probes) extraorally and intraorally, using two different ultrasonography systems. For intra- and interobserver agreements for each probe types, Kappa coefficients were calculated. Results: The lowest ICC values were found in both intra- $($ ICC $=0.696)$ and interobserver reliability $($ ICC $=0.762)$ obtained with the extraorally used linear probe. There was a high agreement with the gold standard when using hockey sticky probes intraorally. For both linear probes, there were no significant differences in agreement among the two observers and the gold standard $(p>0.05)$. Conclusions: High agreement was found when using high-frequency hockey stick probes intraorally, which means that they can be used with good effect for the evaluation of the visibility of peri-implant bone defects. To the best of our knowledge, this study is the first one on this subject. Thus, it can be stated that US can be an alternative method of examining defects. However, further studies are needed to evaluate the effectiveness of US in visualizing peri-implant bone defects.
\end{abstract}

\section{Introduction}

For the success of dental implants, the implant surface must be covered with bone. There is a positive correlation between alveolar bone thickness and primary osteointegration $^{(1,2)}$. Peri-implant defects are supportive bone tissue loss with a prevalence ranging from $28 \%$ to $56 \% \%^{(3)}$. Routine radiographic evaluations are a technique used to evaluate whether peri-implantitis develops. When peri-implantitis goes unnoticed early on, marginal bone loss progresses and leaves the clinician with increasingly narrowing treatment options. From the patient's point of view, there will be a decrease in the quality of final oral rehabilitation unless the condition is promptly addressed ${ }^{(4)}$.
Intraoral and panoramic radiography techniques show the mesial and distal areas of the bone $\mathrm{e}^{(5)}$; but there can be geometric distortions and anatomical superimpositions ${ }^{(6)}$. If 3-dimensional observation of the bone is necessary, conventional and cone-beam computed tomography (CBCT) can provide alternative options ${ }^{(7)}$. There are certain major limitations of these techniques, though, including their high cost, increased radiation exposure, and formation of metal $\operatorname{artifacts}^{(8)}$.

In view of such disadvantages of $\mathrm{CBCT}$, the effectiveness of ultrasonography (US) on bone surface evaluation, bone thickness measurement, and peri-implant defects visibility has started to be evaluated in the literature in recent years ${ }^{(9-12)}$. It is reported that US is the preferred modality due to its 
advantages such as non-invasive nature, use of non-ionizing radiation, good tolerability by patients, and low $\operatorname{cost}^{(13,14)}$.

US is based on the principle of measuring the energy loss caused by the emission, reflection, and scattering of acoustic waves lower than $20 \mathrm{kHz}$ in different tissues. The energy loss of the wave propagating throughout the tissue is associated with the acoustic properties of the waves ${ }^{(15)}$. Due to the highfrequency mode on US, the depth of signal penetration into the tissue decreases, but the image quality is improved. This means that there is an inverse correlation between the image resolution and the measured depth. It has been reported in the literature that high-frequency ultrasounds can be used to scan the bone surface ${ }^{(16)}$. In another study, it was found that the combined use of high- and low-frequency ultrasound may be a new approach in cortical bone evaluation ${ }^{(9)}$.

The present study aimed to evaluate the efficacy of intraoral and extraoral US evaluations performed with two different types of probes (linear and hockey stick) for the visibility of peri-implant bone defects.

\section{Material and methods}

This study was carried out using three sheep heads including soft tissues with 14 implants [zirconium $(n=2)$ titanium implants $(n=12)]$. Before starting the implant surgery, CBCT scanning was done (Planmeca 3D max, Helsinki, Finland) with the following exposure parameters: $96 \mathrm{kVp}$, $12 \mathrm{~mA}$, and $18 \mathrm{~s}$ from each sheep head to plan and identify the implant sites properly. A radiologist with 10 years' experience in oral and maxillofacial radiology performed the implant surgery as well as defect creations. The implants were inserted with a sub-crestal incision to reflect the mucoperiosteal flap. The osteotomy was performed using a pilot drill, and after that sequential drilling was done to prepare the area, taking into account the size of the implant. Copious irrigation with saline was done during the surgical procedure. The implant was inserted with the help of an insertion tool and a torque wrench. Following dental implant placement, the same radiologist created standardized defects around the dental implants. These simulated defects were created only in the buccal surfaces of the implants, app. $3 \mathrm{~mm}$ in diameter and semi-elliptical in form, with high-speed equipment, using copious air/water spray and rounded diamond burs (KG Sorensen, Zenith Dental ApS, Agerskov, Denmark). A total of 9 fenestrations (all buccal surfaces) were created, while 5 surfaces were free of fenestrations and used as a control group. The bone defects were created without knowing the depth. After creating the defects the around dental implants, the mucoperiosteal flap was closed. Care was taken not to damage the gingiva around the implants. The defects noted by the same radiologist served as the gold standard for US imaging.

\section{Imaging modalities}

Two US consoles (ProSound Alpha 6, Hitachi Aloka Medical Ltd., Tokyo, Japan) with a hockey stick intra-operative probe, 13 MHz (UST-536, Hitachi Aloka Medical Ltd., Tokyo, Japan), and a linear probe, 5-13.3 MHz (UST5413, Hitachi Aloka Medical Ltd., Tokyo, Japan), and also a high-resolution ACUSONS 2000 ultrasound unit (Siemens, Munich, Germany) with a 4-9 MHz linear probe (9L4 Transducer) and a hockey stick intra-operative probe $14 \mathrm{MHz}$ (14L5 SP Transducer) were used in the study. All fenestrations and dental implants were scanned both intraorally and extraorally (Fig. 1, Fig. 2, Fig. 3, Fig. 4, Fig. 5). Extraoral scanning was performed with a linear probe, while intraoral scanning was done only with hockey stick probes with a different frequency bandwidth. After adjusting the probe to the desired trajectory, US images were obtained using both probes. Two observers (H.K., K.O) carried out all US scanning and evaluations. The observers were dentomaxillofacial radiologists with 10 years' and 18 years' of experience with US, respectively.

The two observers conducted two separate US sessions independently. The study was performed twice, with an interval of 2 weeks after the initial US scanning. The same sheep heads were used for both US scanning procedures. The observers were free to position the probe when taking images.

\section{Image analysis}

Before the US evaluations, both observers were trained to appropriately use the US software in a special session. However, no calibration was made for the US evaluations since the scanning itself was in real-time. The fenestration defects were detected simultaneously in each US session during scanning, so the detection of defects was done in real-time while scanning. US system proprietary software was used (Hitachi Aloka Medical Ltd., Tokyo, Japan, Siemens S2000, Munich, Germany). The observers were free to use any enhancement procedure that was available in the US unit. Moreover, the observers were aware of the existence of the defects, however they did not know the dental implant type (titanium or zirconium).

For all imaging methods, a five-point scale was used to assess the visibility of each fenestration: (1) definitely absent; (2) probably absent; (3) unsure; (4) probably present; (5) definitely present.

\section{Examiner reliability and statistical analysis}

Intraclass Correlation (ICC) analysis was used for the assessment of intraobserver and intraobserver reliability. Kappa coefficients were calculated to evaluate the gold standard and the observers' agreements for each image set. Kappa values were interpreted according to the guidelines proposed by Landis and $\operatorname{Koch}^{(17)}$, and adapted by Altman ${ }^{(18)} \kappa \leq 0.20$, poor; $\kappa=0.21-0.40$, fair; $\kappa=0.41-0.60$, moderate; $\kappa=0.61-0.80$, good; and $\kappa=0.81-1.00$, very good. Scores obtained from the (1) $1^{\text {st }}$ linear probe extraorally; (2) $2^{\text {nd }}$ linear probe extraorally; (3) $1^{\text {st }}$ hockey stick probe intraorally; and (4) $2^{\text {nd }}$ hockey stick probe intraorally were compared with the gold standard. A probability level of less than $5 \%(p<0.05)$ was accepted as 


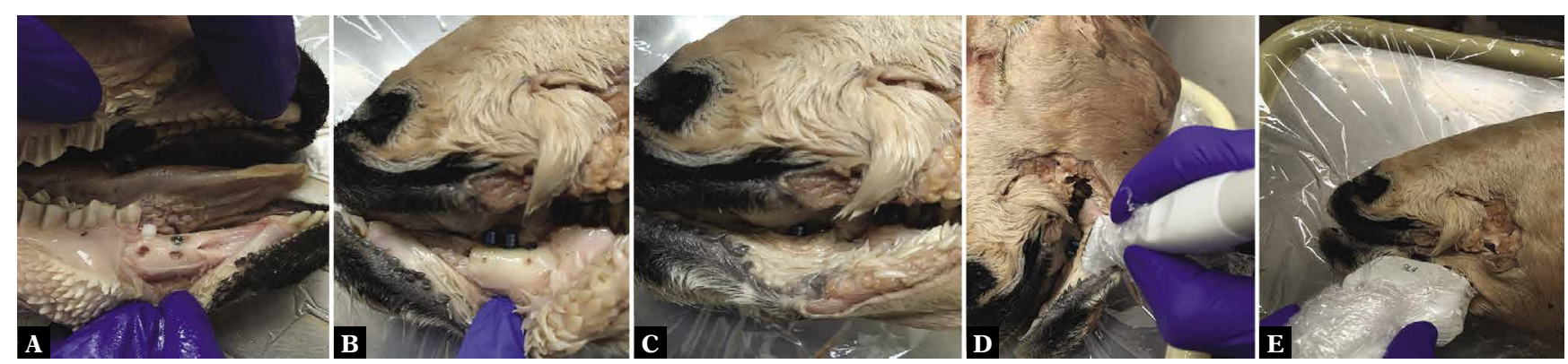

Fig. 1. A. Image using both zirconium and titanium implants with fenestrations, B. Fenestration defects around titanium implants, C. Preparation of scanning site; note that the flap was again placed on the scanned region, D. Intra-oral scan, E. Extra-oral scanning of the dental implant sites

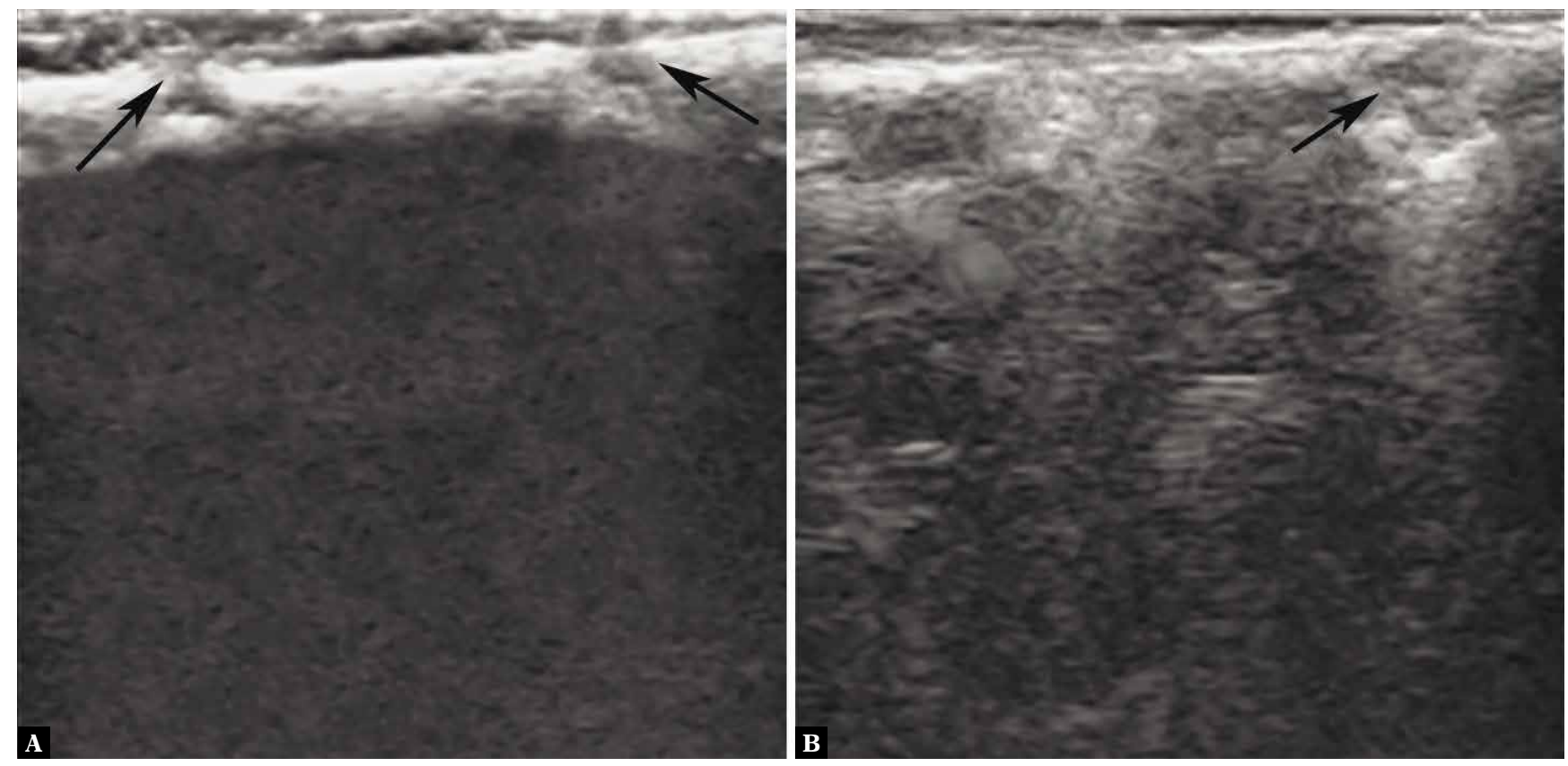

Fig. 2. A. US image showing fenestration defects around titanium implants (arrows), B. US showing a fenestration defect around zirconium implant (arrow) scanned with a $13 \mathrm{MHz}$ intra-operative probe that was used intraorally

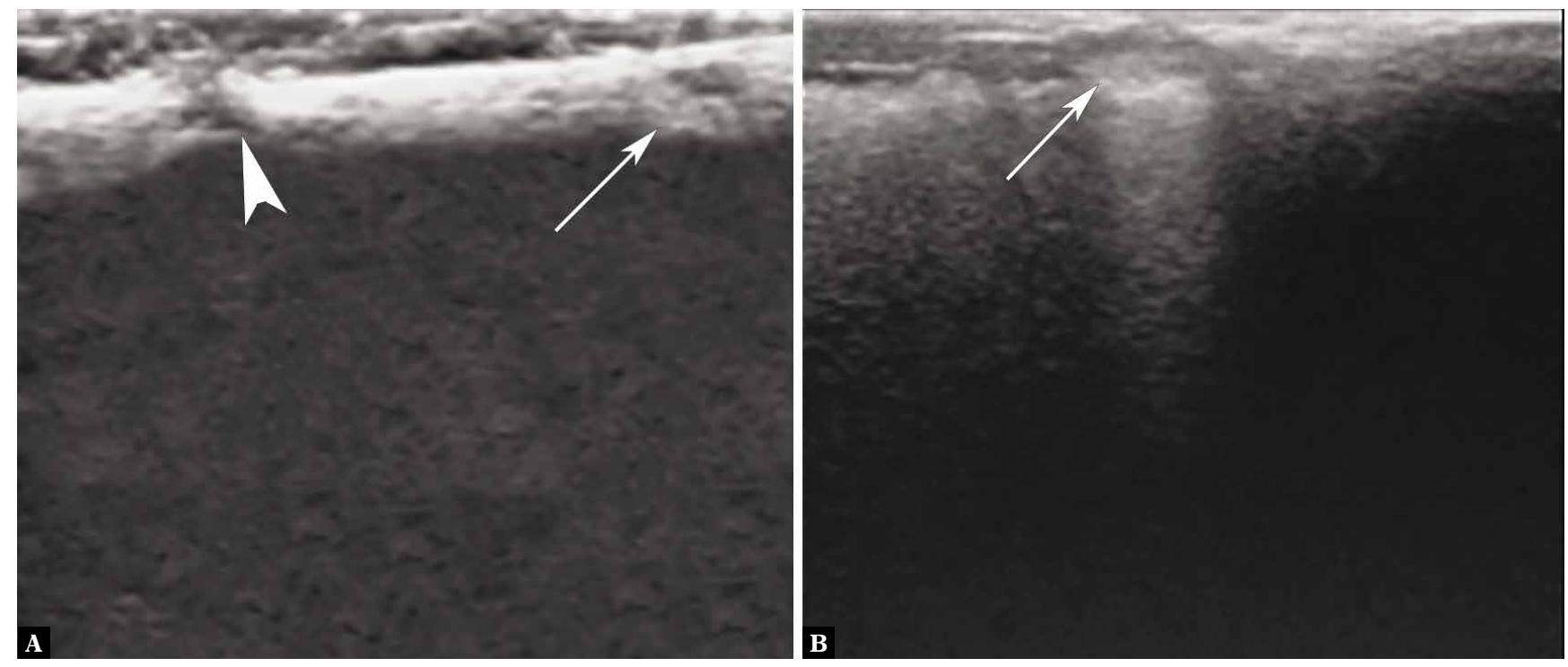

Fig. 3. A. US image showing a fenestration defect around titanium implant (arrowhead), while the fenestration defects were non-visible around $\mathbf{A}$. titanium and $\mathbf{B}$. zirconium implant scanned with a 5-13.3 $\mathrm{MHz}$ linear probe that was used extraorally (arrows) 


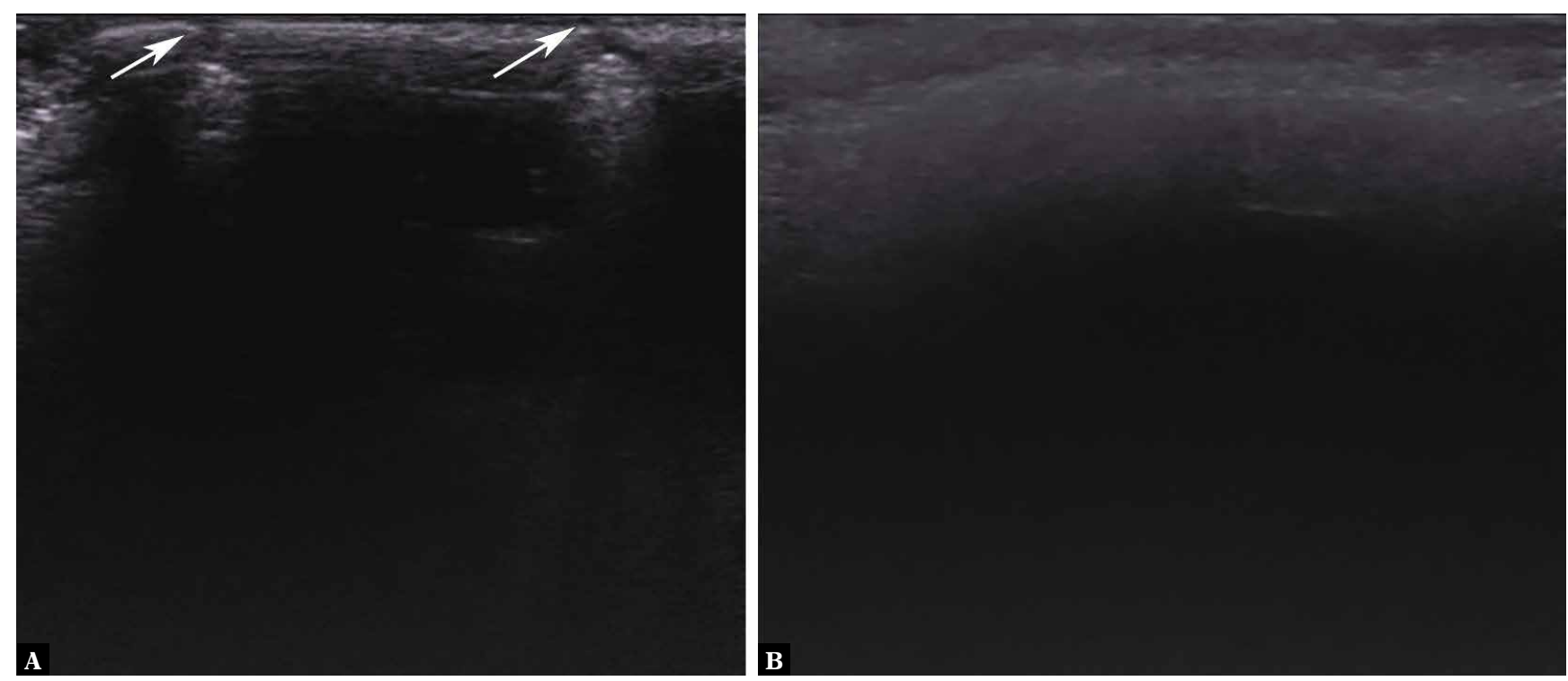

Fig. 4. A. US image showing fenestrations around titanium (left arrow) and zirconium implant (right arrow) scanned with a 14 MHz intra-operative probe, B. Same implants scanned with a 4-9 MHz. linear probe that was used extraorally without any fenestration defect visible
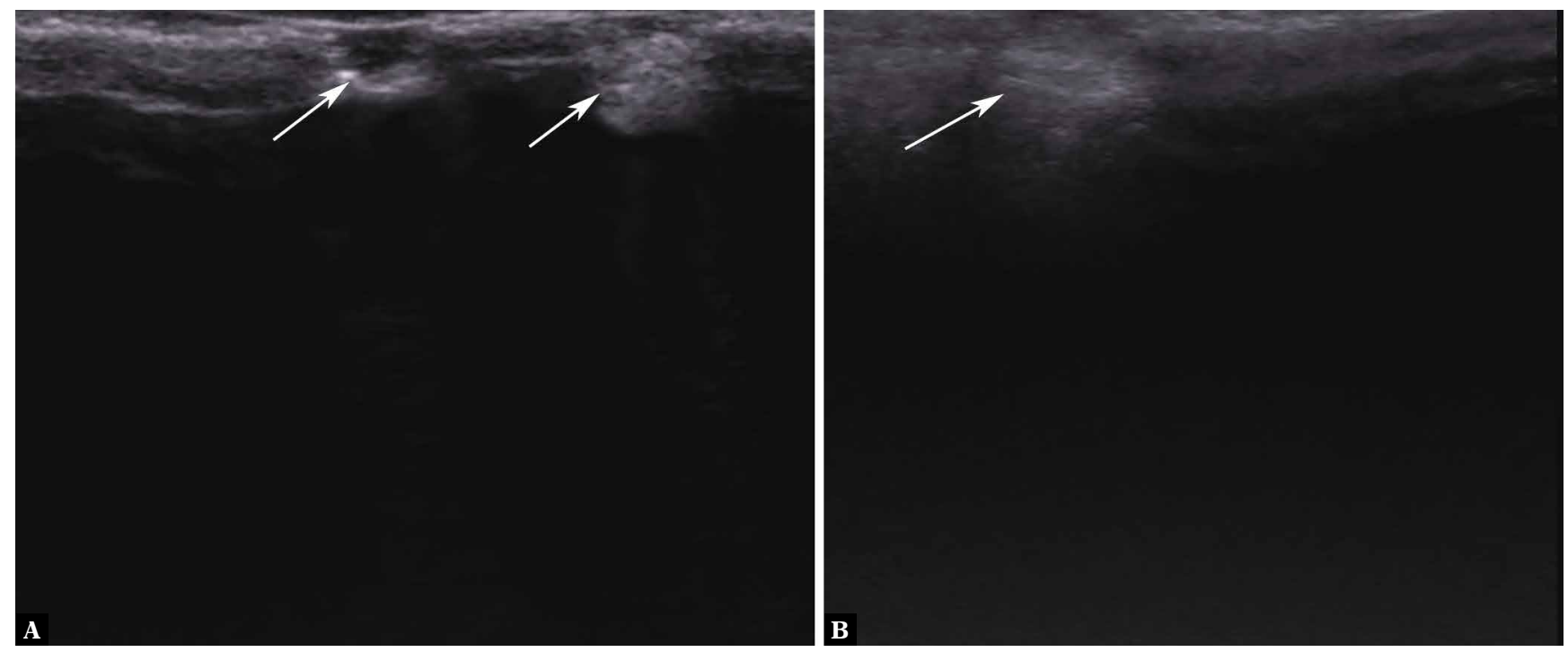

Fig. 5. A. US image showing fenestrations around titanium implants scanned with a $14 \mathrm{MHz}$ intra-operative probe, B. Same implants scanned with a 4-9 $\mathrm{MHz}$, linear probe that was used extraorally with the defect

statistically significant. Statistical analyses were performed using SPSS 21.0 software (SPSS Inc., Chicago, IL, USA).

Tab. 1. Intraobserver agreement for Observer 1 and Observer 2. $p$ value less than 0.05 considered as statically significant (95\% CI)

\begin{tabular}{|c|c|c|c|c|}
\hline & \multicolumn{2}{|c|}{ Observer $\mathbf{1}$} & \multicolumn{2}{c|}{ Observer $\mathbf{2}$} \\
\cline { 2 - 5 } & ICC & $\boldsymbol{p}$ & ICC & $\boldsymbol{p}$ \\
\hline $\begin{array}{c}\mathbf{1}^{\text {st }} \text { hockey stick } \\
\text { probe intraorally }\end{array}$ & $\begin{array}{c}0.878 \\
(0.632-0.960)\end{array}$ & 0.0001 & $\begin{array}{c}0.952 \\
(0.817-0.986)\end{array}$ & 0.001 \\
\hline $\begin{array}{c}\mathbf{2}^{\text {nd }} \text { hockey stick } \\
\text { probe intraorally }\end{array}$ & $\begin{array}{c}0.966 \\
(0.885-0.989)\end{array}$ & 0.0001 & $\begin{array}{c}0.921 \\
(0.752-0.975)\end{array}$ & 0.001 \\
\hline $\begin{array}{c}\mathbf{1}^{\text {st }} \text { linear probe } \\
\text { extraorally }\end{array}$ & $\begin{array}{c}0.696 \\
(0.095-0.901)\end{array}$ & 0.019 & $\begin{array}{c}0.727 \\
(0.120-0.913)\end{array}$ & 0.016 \\
\hline $\begin{array}{c}\mathbf{2}^{\text {nd }} \text { linear probe } \\
\text { extraorally }\end{array}$ & $\begin{array}{c}0.849 \\
(0.524-0.952)\end{array}$ & 0.001 & $\begin{array}{c}0.875 \\
(0.609-0.960)\end{array}$ & 0.001 \\
\hline \multicolumn{4}{|c|}{} \\
\hline \multicolumn{4}{|c|}{}
\end{tabular}

\section{Results}

The lowest ICC value in the intraobserver reliability assessment was obtained with a linear probe (UST-5413) that was used extraorally. The highest ICC value in the intraobserver reliability assessment was obtained with a $14 \mathrm{MHz}$ (14L5 SP Transducer) hockey stick probe (0.966) for Observer 1, and with a $13 \mathrm{MHz}$ (UST-536 Transducer) hockey stick probe that was used intraorally (0.952) for Observer 2 (Tab. 1).

The interobserver ICC coefficients were presented in Tab. 2. Good interobserver reliability was achieved in all probes with ICC values between 0.762 and 0.914 . The linear probe (UST-5413) that was used extraorally had the lowest interobserver reliability (Tab. 2). 
Tab. 2. Interobserver agreement between observers. $p$ value less than 0.05 considered as statically significant $(95 \%$ CI)

\begin{tabular}{|c|c|c|}
\hline & ICC & $\boldsymbol{p}$ \\
\hline $\begin{array}{c}\mathbf{1}^{\text {st }} \text { hockey stick probe } \\
\text { intraorally }\end{array}$ & $0.784(0.349-0.930)$ & 0.002 \\
\hline $\begin{array}{c}\mathbf{2}^{\text {nd }} \text { hockey stick probe } \\
\text { intraorally }\end{array}$ & $0.909(0.721-0.971)$ & 0.001 \\
\hline $\mathbf{1}^{\text {st }}$ linear probe extraorally & $0.762(0.300-0.922)$ & 0.006 \\
\hline $\mathbf{2}^{\text {nd }}$ linear probe extraorally & $0.914(0.728-0.972)$ & 0.001 \\
\hline
\end{tabular}

The $13 \mathrm{MHz}$ hockey stick intraoral probe (UST-536 Transducer) had a high level of agreement with the gold standard $(p<0.05 ; \kappa=0.837)$, while the other hockey stick intraoral probe showed a moderate to high agreement with the gold standard for Observer $1(p<0.05 ; \kappa=0.689)$. No significant differences were found in the agreement between Observer 1 and the gold standard for the linear probes that were used extraorally $(p>0.05)$ (Tab. 3$)$.

The agreement between Observer 2 with the gold standard was high ( $p<0.05 ; \kappa=0.851$ and 0.714 , respectively) for both hockey stick probes used intraorally, while again no significant differences were noted in terms of agreement between Observer 2 and the gold standard for the linear probes that were used extraorally $(p>0.05)$ (Tab. 3).

\section{Discussion}

Early diagnostic criteria of peri-implantitis include radiographic bone loss greater than one-third of implant height ${ }^{(19)}$. For this reason, it is important to monitor bone loss in the follow-up period after the operation ${ }^{(20)}$. In dentistry, radiographic examination is the most common choice to evaluate peri-implantitis ${ }^{(5)}$. In the metaanalysis of Bohner et al. ${ }^{(21)}$, the majority of the reviewed studies used $\mathrm{CBCT}$ or intraoral radiography to diagnose peri-implant bone defects. However, Bornstein et al. (22) reported that the evaluation of bone around dental implants was limited due to the formation of beam-hardening artifacts. In recent years, the question of whether bone defects can be examined without using ionizing radiation has started to be investigated, with the conclusion that US is a promising technique for the evaluation of bone defects and soft tissue pathologies caused by surgical complications $^{(23)}$.
To the best of our knowledge, there are only a few studies on bone surfaces with evaluations performed using US $^{(9,13,16,24)}$. In their study, Degen et al..$^{(9)}$ compared low- and high-frequency US to CBCT in measuring cortical bone thickness, concluding that US can assist CBCT in measuring bone thickness. Bohner et al. ${ }^{(10)}$ used CBCT, Micro-CT, and US to evaluate peri-implant bone defects, and reported that US underestimated the measurements for the supraalveolar and intra-bony surfaces, compared with CBCT and Micro-CT. Also, it was found that US was accurate in measurements of the width of peri-implant defects, although vertical measurements were underestimated by about $1 \mathrm{~mm}$ compared to those performed with CBCT and Micro-CT ${ }^{(10)}$. In the study of Choi et al. ${ }^{(25)}$, US was found to be capable of showing representative features for implant planning in a porcine model; these included implants that were placed in edentulous ridges; implants for single missing teeth; implants and teeth with simulated dehiscences; and mental foramina.

Several studies have explored the effect of probes of different frequencies on the quality of imaging periodontal defects. Mahmoud et al. (24) investigated the effectiveness of high- and low-frequency probes in imaging periodontal diseases. The authors stated that high-frequency probes were more effective in detecting periodontal diseases early. Similarly, Chifor et al. ${ }^{(26)}$ reported that using high-frequency probes was more effective in imaging periodontal bone defects. However, no study comparing the effectiveness of the intraoral probe and linear probe in the visibility of defects has been found. Therefore, the aim of this study was to investigate the effectiveness of different probes in the visibility of peri-implant defects.

СBCT can also be used routinely for detecting these kinds of defects. However, the occurrence of metal artifacts around dental implants, as scattering or complete absorption of the beam can exist and be concluded with image degradation. This situation can prevent the observation of the implant-bone interface, and make it difficult to evaluate peri-implant bone defects ${ }^{(27,28)}$. In the head and neck area, high-resolution images in multiple planes are obtained with modern US units with high-frequency linear probes $(7.5-12 \mathrm{MHz})^{(29)}$. In dental practice, US is mainly used in cases of maxillofacial fractures ${ }^{(30)}$, cervical lymphadenopathy ${ }^{(31)}$, soft tissue masses ${ }^{(32)}$, masticatory and neck muscles ${ }^{(33,34)}$, temporomandibular joint ${ }^{(35)}$,

Tab. 3. Comparison of observers with the gold standard. $p$ value less than 0.05 considered as statically significant

\begin{tabular}{|c|c|c|c|c|c|c|c|}
\hline & & Sensitivity & Specificity & PPV & NPV & к & $p$ \\
\hline $1^{\text {st }}$ hockey stick probe intraorally & Observer 1-Gold Standard & $80 \%$ & $100 \%$ & $100 \%$ & $90 \%$ & 0.837 & 0.001 \\
\hline $2^{\text {nd }}$ hockey stick probe intraorally & Observer 1-Gold Standard & $80 \%$ & $89 \%$ & $80 \%$ & $89 \% \mathrm{hz}$ & 0.689 & 0.011 \\
\hline $1^{\text {st }}$ linear probe extraorally & Observer 1-Gold Standard & $100 \%$ & $33 \%$ & $46 \%$ & $100 \%$ & 0.263 & 0.145 \\
\hline $2^{\text {nd }}$ linear probe extraorally & Observer 1-Gold Standard & $100 \%$ & $33 \%$ & $46 \%$ & $100 \%$ & 0.263 & 0.145 \\
\hline $1^{\text {st }}$ hockey stick probe intraorally & Observer 2-Gold Standard & $100 \%$ & $89 \%$ & $83 \%$ & $100 \%$ & 0.851 & 0.001 \\
\hline $2^{\text {nd }}$ hockey stick probe intraorally & Observer 2-Gold Standard & $100 \%$ & $78 \%$ & $71 \%$ & $100 \%$ & 0.714 & 0.005 \\
\hline $1^{\text {st }}$ linear probe extraorally & Observer 2-Gold Standard & $60 \%$ & $22 \%$ & $30 \%$ & $50 \%$ & -0.145 & 0.481 \\
\hline $2^{\text {nd }}$ linear probe extraorally & Observer 2-Gold Standard & $80 \%$ & $11 \%$ & $33 \%$ & $50 \%$ & -0.068 & 0.649 \\
\hline
\end{tabular}


periapical $^{(36,37)}$ salivary gland diseases ${ }^{(38)}$, intraosseous jaw pathologies $^{(39)}$, and carotid paragangliomas ${ }^{(40)}$.

There are several limitations of this study. Firstly, two different ultrasound systems with probes slightly differing in frequency were used. Although the frequencies of probes are similar to each other, they may still influence the results obtained. This can be due to the value of the signal to noise ratio (SNR) which increases as the frequency of the ultrasound signal rises. It was stated that less speckle noise was produced as higher frequency signal was applied ${ }^{(41)}$. In a recent paper, it was also found that lower frequency may achieve a better depth penetration, while higher frequencies are associated with better resolution. While the output power may improve image quality by increasing the intensity of transmitted sound energy, the impact is usually insignificant ${ }^{(42)}$. This issue can be addressed in more depth in future studies.

Another limitation of this study is that even though two observers performed two separate US sessions independently, observational differences in US can affect the results. Also, no comparison was performed for implant types (zirconia and titanium implants). Since the number of implants of both

\section{References}

1. Demircan S, Demircan E: Dental cone beam computed tomography analyses of the anterior maxillary bone thickness for immediate implant placement. Implant Dent 2015; 24: 664-668.

2. Andrés-García R, Vives NG, Climent FH, Palacín AF, Santos VR, Climent $\mathrm{MH}$ et al.: Invitro evaluation of the influence of the cortical bone on the primary stability of two implant systems. Med Oral Patol Oral Cir Bucal 2009; 14: E93-97.

3. Lindhe J, Meyle J, Group D of European Workshop on Periodontology: Peri-implant diseases: Consensus report of the sixth European workshop on periodontology. J Clin Periodontol 2008; 35: 282-285.

4. Harris D, Horner K, Grondahl K, Jacobs R, Helmrot E, Benic GI et al.: E.A.O. guidelines for the use of diagnostic imaging in implant dentistry. A consensus workshop organized by the European Association for Osseointegration at the Medical University of Warsaw. Clin Oral Implants Res 2012; 23: 1243-1253.

5. Kuhl S, Zürcher S, Zitzmann NU, Filippi A, Payer M, Dagassan-Berndt D: Detection of peri-implant bone defects with different radiographic techniques - a human cadaver study. Clin Oral Implants Res 2016; 27: 529-534.

6. García-García M, Mir-Mari J, Benic GI, Figueiredo R, Valmaseda-Castellon E: Accuracy of periapical radiography in assessing bone level in implants affected by peri-implantitis: a cross-sectional study. J Clin Periodontol 2016; 43: 85-91.

7. Dave M, Davies J, Wilson R, Palmer R: A comparison of cone beam computed tomography and conventional periapical radiography at detecting peri-implant bone defects. Clin Oral Implants Res 2013; 24: 671-678.

8. Golubovic V, Mihatovic I, Becker J, Schwarz F: Accuracy of cone-beam computed tomography to assess the configuration and extent of ligature-induced peri-implantitis defects. A pilot study. Oral Maxillofac Surg 2012; 16: 349-354.

9. Degen K, Habor D, Radermacher K,Heger S, Kern JS, Wolfart S et al:: Assessment of cortical bone thicknessusingultrasound. Clin Oral Implants Res 2017; 28: 520-528.

10. Bohner L, Habor D, Gremse F, Tortamano P, Wolfart S, Marotti J: Accuracy of high-frequency ultrasound scanner in detecting peri-implant bone defects. Ultrasound Med Biol 2019; 45: 650-659.

11. Demiralp KO, Orhan K, Kurşun-Çakmak EŞ, Gorurgoz C, Bayrak S: Comparison of cone beam computed tomography and ultrasonography types in this study is not sufficient, the comparison between them has not been studied statistically. However, further studies with more implant types and numbers should be done to elucidate the differences between implant types in US images.

\section{Conclusion}

Hockey stick probes used intraorally can be an effective option for the evaluation of the visibility of peri-implant bone defects. No report was found in the literature regarding a comparison of peri-implant bone defect visibility with different US probes. To the best of our knowledge, this study is the first one addressing this subject. Thus, the conclusion is that US can be an alternative method of evaluating defects. However, further studies are needed to determine the effectiveness of US in the visualization of peri-implant bone defects.

\section{Conflict of interest}

Authors do not report any financial or personal connections with other persons or organizations which might negatively affect the contents of this publication and/or claim authorship rights to this publication. with two types of probes in the detection of opaque and non-opaque foreign bodies. Med Ultrasound 2018; 20: 467-474.

12. Marotti J, Neuhaus S, Habor D, Bohner L, Heger S, Radermacher K et al.: High-frequency ultrasound for assessment of peri-implant bone thickness. J Clin Med 2019; 8: 1539.

13. Machtei EE, Zigdon H, Levin L, Peled M: Novel ultrasonic device to measure the distance from the bottom of the osteotome to various anatomic landmarks. J Periodontol 2010; 81: 1051-1055.

14. Salmon B, Le Denmat D: Intraoral ultrasonography: development of a specific high-frequency probe and clinical pilot study. Clin Oral Investig 2012; 16: 643-649.

15. Marotti J, Heger S, Tinschert J, Tortamano P, Chuembou F, Radermacher $\mathrm{K}$ et al.: Recent advances of ultrasound imaging in dentistry a review of the literature. Oral Surg Oral Med Oral Pathol Oral Radiol 2013; 115: 819-832.

16. Habor D, Neuhaus S, Vollborn T, Wolfart S, Radermacher K, Heger $\mathrm{S}$. Model based assessment of vestibular jawbone thickness using high frequency 3-D ultrasound micro-scanning. In: Proc 8675, SPIE Medical Imaging 2013: Ultrasonic Imaging, Tomography, and Therapy, 86750Z.

17. Landis JR, Koch GG: The measurement of observer agreement for categorical data. Biometrics 1977; 33: 159-174.

18. Altman DG: Practical Statistics for Medical Research. Chapman and Hall/CRC Press 1990.

19. Albrektsson T, Zarb G, Worthington P, Eriksson AR: The long-term efficacy of currently used dental implants: a review and proposed criteria of success. Int J Oral Maxillofac Implants 1986; 1: 11-25.

20. Schliephake H, Wichmann M, Donnerstag F, Vogt S: Imaging of periimplant bone levels of implants with buccal bone defects. Clin Oral Implants Res 2003; 14: 193-200.

21. Bohner LOL, Mukai E, Oderich E, Porporatti AL, Pacheco-Pereira C, Tortamano $\mathrm{P}$ et al:: Comparative analysis of imaging techniques for diagnostic accuracy of peri-implant bone defects: a meta-analysis. Oral Surg Oral Med Oral Pathol Oral Radiol 2017; 124: 432-440.

22. Bornstein MM, Al-Nawas B, Kuchler U, Tahmaseb A: Consensus statements and recommended clinical procedures regarding contemporary surgical and radiographic techniques in implant dentistry. Int J Oral Maxillofac Implants 2014; 29: 78-82. 
23. Benic GI, Elmasry M, Hammerle $\mathrm{CH}$ : Novel digital imaging techniques to assess the outcome in oral rehabilitation with dental implants: a narrative review. Clin Oral Implants Res 2015; 26: 86-96.

24. Mahmoud AM, Ngan P, Crout R, Mukdadi OM: High-resolution 3D ultrasound jawbone surface imaging for diagnosis of periodontal bony defects: an in vitro study. Ann Biomed Eng 2010; 38: 3409-3422.

25. Choi M, Culjat MO, Singh RS, White SN.: Ultrasound imagery for dental implant diagnosis and treatment planning in a porcine model. J Prosthet Dent 2012; 108: 344-353.

26. Chifor R, Hedeşiu M, Bolfa P, Catoi C, Crişan M, Serbănescu A et al.: The evaluation of $20 \mathrm{MHz}$ ultrasonography, computed tomography scans as compared to direct microscopy for periodontal system assessment. Med Ultrason 2011; 13: 120-126.

27. Benic GI, Sancho-Puchades M, Jung RE, Deyhle H, Hammerle CH: In vitro assessment of artifacts induced by titanium dental implants in cone beam computed tomography. Clin Oral Implants Res 2013; 24: 378-383.

28. Pauwels R, Stamatakis H, Bosmans H, Bogaerts R, Jacobs R, SEDENTEXCT Project Consortium et al.: Quantification of metal artifacts on cone beam computed tomography images. Clin Oral Implants Res 2013; 24: 94-99.

29. Oeppen RS, Gibson D, Brennan PA: An update on the use of ultrasound imaging in oral and maxillofacial surgery. Br J Oral Maxillofac Surg 2010; 48: 412-418.

30. Akizuki H, Yoshida H, Michi K: Ultrasonographic evaluation during reduction of zygomatic arch fractures. J Craniomaxillofac Surg 1990; 18: 263-266.

31. Benson BW, Flint DJ, Liang H, Opatowsky MJ: Advances in diagnostic imaging for pathologic conditions of the jaws. Head Neck Pathol 2014; 8: 383-391.

32. Ahuja AT, Ying M, Ho SY, Antonio G, Lee YP, King AD et al.: Ultrasound of malignant cervical lymph nodes. Cancer Imaging 2008; 8: 48-56.
33. Uchida Y, Motoyoshi M, Shigeeda T, Shinohara A, Igarashi Y, Sakaguchi $\mathrm{M}$ et al.: Relationship between masseter muscle size and maxillary morphology. Eur J Orthod 2011; 33: 654-659.

34. Naser-ud-Din S, Thoirs K, Sampson WJ: Ultrasonography, lateral cephalometry and 3D imaging of the human masseter muscle. Orthod Craniofac Res 2011; 14: 33-43.

35. Bas B, Yılmaz N, Gökce E, Akan H: Diagnostic value of ultrasonography in temporomandibular disorders. J Oral Maxillofac Surg 2011; 69: 1304-1310.

36. Raghav N, Reddy SS, Giridhar AG, Murthy S, Yashodha Devi BK, Santana $\mathrm{N}$ et al:: Comparison of the efficacy of conventional radiography, digital radiography, and ultrasound in diagnosing periapical lesions. Oral Surg Oral Med Oral Pathol Oral Radiol Endod 2010; 110: 379-385.

37. Tikku AP, Kumar S, Loomba K, Chandra A, Verma P, Aggarwal R: Use of ultrasound, color Doppler imaging and radiography to monitor periapical healing after endodontic surgery. J Oral Sci 2010; 52: 411-416.

38. Caglayan F, Bayrakdar IS: The intraoral ultrasonography in dentistry. Niger J Clin Pract 2018; 21: 125-133.

39. Bayrakdar IS, Yılmaz AB, Kaplan FA, Bilgir E, Orhan K: Evaluation of the snowing-like ultrasonographic features of intraosseous jaw pathologies. J Ultrason 2021; 20: e307-e310.

40. Delantoni A, Sarafopoulos A, Polanagnostaki A, Orhan K: B-mode and color Doppler imaging of carotid paragangliomas in different neck regions. J Ultrason 2020; 20: e218-e221.

41. Malek SN, Sayed IS. Multi-frequency ultrasound imaging: phantom study. Int J Allied Health Sci 2018; 2: 304-309.

42. Wiafe YA, Badu-Peprah A: The influence of ultrasound equipment knobology in abdominal sonography. In: S.A.A. Gamie, E.M. Foda (ed.): Essentials of Abdominal Ultrasound. Intech Open 2019. DOI: 10.5772/ intechopen.83713. 